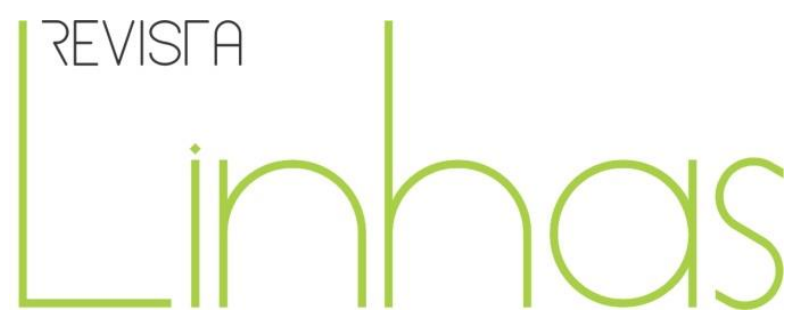

\title{
La necesidad de educar en comunicación digital en la sociedad global
}

\section{Resumen}

La sociedad actual basa su funcionamiento en las Tecnologías de la Información y de la Comunicación, donde la intercomunicación es continua. Los centros educativos, como organizaciones que son y que han de preparar para el futuro a las actuales generaciones, viven inmersos en un proceso comunicativo que influye en sus resultados, dentro de un mundo en el que la información es digital y global. Educación y comunicación se interrelacionan en su esencia y en sus finalidades. Ambas se necesitan porque en el fondo comparten objetivos comunes. En este artículo trataremos, de entrada, sobre los centros educativos como centros comunicativos en una sociedad global, un concepto básico y a veces descuidado, sobre el que se apoyan las actuaciones comunicativas digitales en este modelo de sociedad. También nos referiremos a otras manifestaciones comunicativas que se dan en los centros modernos pertenecientes a la sociedad postindustrial y con las que no solo hay que convivir sino también sobre las que hay que educar. Nos detendremos en el periodismo digital como factor potenciador de la "Educomunicación", hablaremos de la importancia de las redes sociales y su uso en los centros educativos y acabaremos enmarcando algunos aspectos sobre los dispositivos móviles y su potencial educativo desde la comunicación.

Palabras clave: Comunicación; Educación; Educomunicación.
Evaristo González Prieto

Professor em Instituto de Ensino Público de Terrassa

IES - Torre del Palau. Graduado em Ciências da Informação (Jornalismo) pela Universidade Autônoma de Barcelona Espanha evaristogonzal@gmail.com

\section{Para citar este artigo:}

PRIETO, Evaristo González. La necesidad de educar en comunicación digital en la sociedad global. Revista Linhas. Florianópolis, v. 17, n. 33, p. 08-28, jan./abr. 2016. 


\section{The need for education in digital communication in our global society}

\begin{abstract}
Our current society is based on Information and Communication technologies, where intercommunication is continuous. Schools and colleges, which must prepare present generations for the future, live in a dense communicative process which influences student's results in our digital and global society. Education and communication are interconnected in their essence and objectives. Both need one another because, in fact, they share common objectives. In this article, we are going to deal with schools as communicative centres in a global society, a basic and sometimes neglected concept. This concept is pivotal in digital communicative scenarios in our role of society. We will also cover other communicative situations in our modern post-industrial schools, which we have to handle and teach students to manage into their lives. We will discuss digital journalism as a facilitator of "educommunication" and we will also deal with the importance of social networks and their use in the academic world. We will finish the article with a framework of some aspects about the use of mobile devices and their educative potential in communication.
\end{abstract}

Keywords: Communication; Education; Educommunication.

\section{A necessidade de educar sobre comunicação digital na sociedade global}

\begin{abstract}
Resumo
A sociedade atual se fundamenta nas Tecnologias da Informação e da Comunicação, resultando em intercomunicação contínua. Os centros educacionais, como organizações que são e que têm de preparar para o futuro as atuais gerações, vivem imersos em um processo comunicativo que influi em seus resultados, dentro de um mundo em que a informação é digital e global. Educação e comunicação se inter-relacionam em sua essência e em suas finalidades. Uma necessita da outra, porque no fundo compartilham objetivos comuns. Neste artigo, trataremos, de saída, dos centros educacionais como centros comunicativos em uma sociedade global, um conceito básico e às vezes negligenciado, sobre o qual se apoiam as atuações comunicativas digitais neste modelo de sociedade. Também nos referiremos a outras manifestações comunicativas que se dão nos centros modernos pertencentes à sociedade pós-industrial e com as quais não só é preciso conviver, mas também é preciso educar sobre elas. Ater-nos-emos no periodismo digital como fator potencializador da "Educomunicação", falaremos da importância das redes sociais e seu uso nos centros educacionais e acabaremos enquadrando alguns aspectos sobre os dispositivos móveis e seu potencial educativo a partir da comunicação.
\end{abstract}

Palavras-chave: Comunicação; Educação; Educomunicação. 
El punto de partida para este artículo son las ideas del gran educador brasileño Paulo Freire recogidas por FERNÁNDEZ (1999), que deberían estar muy vigentes hoy día. Reflexionaba sobre la relación entre comunicación, educación y sociedad (que debe ser de total implicación) y consideraba al hombre y a la mujer como seres biológicos e históricos que necesitan relacionarse y contactar con otras personas. ( ${ }^{1}$ )

La sociedad actual depende cada vez más de las Tecnologías de la Información y de la Comunicación (TIC) para su funcionamiento en un marco global. El mundo funciona a través de redes interconectadas que están sometidas a un tráfico constante de información y de datos. Las más generalistas son públicas, al alcance de cualquier persona, con las que podemos desempeñar un doble papel: ser solo sujetos pasivos o participar de forma activa: interactuar, producir nuevas informaciones, compartirlas e influir en las sinergias comunicativas globales. La diversidad de opiniones en torno a la realidad digital provoca posturas contrapuestas, defendidas con argumentaciones interesantes. El experto CARR (2011) ha mostrado preocupación por los cambios de hábitos, por la multiplicidad y exceso de contenidos, por la falta de concentración y por la superficialidad que produce el abuso de las TIC en las personas. Otros especialistas creen en las bondades de la tecnología, dicen que estamos en el inicio de un período de transición y que aún no se ha llegado a situaciones alarmantes (DANS).

La horizontalidad, la democratización y el fácil acceso a los conocimientos en red también afecta a la educación actual (la formal, la no formal y la informal) y tiende, poco a poco, a generar cambios en las metodologías pedagógicas y a renovar las antiguas estructuras de la enseñanza. Profesionales que llevan años trabajando con las TIC en el aula opinan que la transformación de los centros educativos en la era digital debería ser

\footnotetext{
${ }^{1}$ Los principios fundamentales de este artículo parten del trabajo efectuado durante el curso 2000-2001 para el Departamento de Enseñanza de la Generalitat de Cataluña (Barcelona, España) titulado "La comunicación global en educación: de las webs a los centros docentes" (GONZÁLEZ, 2001). Aquellos planteamientos, que preveían ya hace quine años la importancia de la comunicación y de los formatos digitales en los centros educativos, se extienden y se amplían hoy a una sociedad aún más global e interconectada. Se han hecho avances en educación pero no los suficientes, teniendo en cuenta la evolución constante de la sociedad, en contraste con la lentitud de la introducción de cualquier cambio en la educación de las futuras generaciones, en contextos pedagógicos a menudo muy conservadores y aferrados a prácticas ancestrales.
} 
una realidad que incumbiera a todos (GONZÁLEZ, 2015a). El marco general es la comunicación global en una sociedad postindustrial también global, con unas herramientas predominantes en todos los sectores: las TIC, sin olvidar que los desequilibrios sociales y económicos prevalecen en una gran cantidad de países, con un gran impacto en la educación. El alumno (en este caso el no universitario) hoy se ve inmerso en múltiples procesos comunicativos, con la posibilidad de seguirlos y participar en cualquier momento (interactividad) y desde cualquier lugar gracias a los dispositivos móviles. Ante una realidad compleja y apasionante, las Instituciones Educativas (IE) le han de aportar pautas para entender e interpretar los procesos comunicativos globales, sometidos a un flujo constante y con impactos inmediatos en el público receptor y, en especial, en la educación. El primer núcleo o red en que el alumnado se encuentra inmerso es la IE donde estudia, una organización que también ha de reflexionar sobre su estructura comunicativa para mejorar.

Realidades como la sobreabundancia de información, su contextualización, el saber cómo se produce, la manipulación o intoxicación por parte de diversos poderes, la publicación inmediata en las redes sociales, la inseguridad, el respeto a la privacidad y a los derechos de autoría exigen actuaciones educativas en comunicación digital, para que el alumno sepa qué tiene en sus manos: grandes herramientas que también sirven para potenciar valores humanos, formarse un espíritu crítico y contribuir a la creación de un mundo mejor.

El alumno actual vive inmerso en un mundo interconectado, lleno de redes que transmiten continuamente información y ofrecen contenidos de diversas clases y con múltiples objetivos. Es la era de un nuevo concepto llamado "Infoxicación” (CORNELLA, 2013). Pero también la familia, el profesorado y el resto de la sociedad forman parte de este entorno complejo en el que los dispositivos y las conexiones múltiples favorecen la formación continua a lo largo de toda la vida, ponen a su alcance recursos e intercomunicación, pero también se originan sinergias dispares y los peligros acechan. Por ejemplo, el efecto que producen los datos que publicamos en la formación de nuestra identidad digital. 
En este artículo trataremos, de entrada, sobre los centros educativos como centros comunicativos en una sociedad global, un concepto básico y a veces descuidado sobre el que se apoyan las actuaciones comunicativas digitales en este modelo de sociedad. También hablaremos de otras manifestaciones comunicativas que se dan en los centros modernos y con las que no solo hay que convivir sino también sobre las que hay que educar. Nos detendremos en el periodismo digital como factor potenciador de la “educomunicación", hablaremos de la importancia de las redes sociales y acabaremos enmarcando algunos aspectos sobre los dispositivos móviles y su potencial educativo desde la comunicación.

\section{La comunicación global en educación}

El primer gran centro comunicativo para el alumno, aparte de la familia y la sociedad que lo envuelve, es la institución escolar. No abundan los estudios y las reflexiones sobre este marco inicial que es tan decisivo en la formación de los ciudadanos. A menudo el profesorado tampoco se para a pensar en la pequeña comunidad donde trabaja (desde el punto de vista de la comunicación), excepto cuando surgen disfunciones que le perjudican o le alteran la normalidad. La comunicación es una de las herramientas y de los soportes que más incumbe al mundo educativo. Todo comunica, incluso se duda de la no comunicación (INFANTE, 1986). Tanto las personas como las organizaciones necesitan de la comunicación para funcionar y los centros educativos la deben usar como un gran instrumento educativo y también con un objetivo para enseñar: que el alumnado aprenda a comunicar y a revertir en la sociedad sus resultados, creaciones y líneas de actuación. El profesor y experto en comunicación SERRANO (2000) entiende la comunicación en un sentido muy amplio y cree que en la educación es donde se sitúa una de sus máximas prioridades: invertir en uno de las recursos más importantes para el cambio social. Ampliando las relaciones, BARTOLI (1992) defiende que la cultura, la organización y la comunicación son estrechamente interdependientes: "Plan de comunicación y plan de organización están íntimamente ligados y producen un impacto transversal en el conjunto". Dentro del esquema organizativo escolar, juegan un papel básico los profesionales implicados, a los que hay que estimular y motivar. Se consigue 
ayudando con herramientas, recursos y formación; no aportando solo ideas o teorías sin soportes prácticos, las cuales suelen recompensar a quien las dice o publica y trasladan el trabajo a quienes apenas disponen de tiempo ni, a veces, formación específica para desarrollarlas. Educación y comunicación caminan de la mano. No se entendería educar sin el factor comunicativo.

Respecto a los Medios de Comunicación de Masas (MCM), hoy afectados por una crisis de identidad y de planteamientos para el futuro debido al impacto y efectos de la comunicación digital en la profesión periodística, con modelos como el periodismo ciudadano, en ciertos sectores de la sociedad se relacionan conceptos como educación, ética y comunicación y les implican por su gran responsabilidad ante la opinión pública. Aparecen interesantes propuestas como la comunicación ética, la responsabilidad de los medios, políticas comunicativas públicas acordes con una forma de proceder concreta o reflexiones sobre cómo educan los medios con sus informaciones, silencios o manipulaciones. En el fondo y en la forma, comunicación y educación se alimentan mutuamente como si fueran unos vasos comunicantes. No se puede pasar por alto el sistema para introducir mensajes de cambio responsable en la sociedad. Cualquier institución que pretenda conseguir ese cambio de actitudes o fijar una forma de actuar diferente recurre a la comunicación. Las cifras dedicadas a convencer con estas técnicas son desorbitantes. Y la mayoría suelen salir de las arcas públicas. Todo ello enmarcado dentro de un entorno comunicativo que intenta abarcar el máximo espectro posible para conseguir mayor impacto. De esta manera aparece el concepto de la comunicación global.

El término Globalidad se ha usado con una acepción económica y política (de tintes a veces negativos, detrás de los cuales existen tendencias económicas neoliberales, muy cuestionadas por sus efectos en las personas) sin olvidar una de sus vertientes principales: lo global sujeto a unas dinámicas comunicativas generalistas de amplio alcance, que suelen partir de lo más local o cercano. Las grandes empresas multinacionales y los países más desarrollados se han apropiado de un término lleno de matizaciones semánticas, con especificaciones que se concretan en servicios cercanos a ciudadanos que buscan y exigen la conectividad las 24 horas de cada día (HERNÁNDEZ, 
2015). Quedemos con lo global en su significado comunicativo, con posibilidades de aplicación educativa. Conceptos clave: global, local, comunicación, educación, dignificación de la comunidad educativa, potenciación de la imagen que la sociedad debe tener del trabajo de los centros educativos: lugares donde se forman los ciudadanos desde el presente. Al final, serán personas preparadas para esa sociedad también global.

En el mundo de las empresas o de cualquier organización más o menos compleja aparece cada vez más la preocupación por el entorno comunicativo. La reflexión suele partir del estrato directivo, teniendo en cuenta la estrecha relación que hay entre los objetivos de tales organizaciones con la mejora de los procesos que conducen a conseguirlos por parte de sus trabajadores. Por eso, tanto en estudios internos, auditorías como en investigaciones efectuadas por personal especializado, aparece el entorno comunicativo. La matización más frecuente se refiere a lo que se denomina “activos intangibles" (FERNÁNDEZ, 2012), vinculados a la llamada comunicación abierta y transparente en una organización regida por principios éticos. En otros ámbitos educativos como el universitario ya se lo han planteado, donde también aparece el mismo aspecto. La comunicación, de por sí básica, se acompaña hoy día en su proyección con la palabra Global.

La comunicación global implica la organización de todos los procesos comunicativos, internos y externos, para conseguir una mayor efectividad en cuanto a funcionamiento y un mejor conocimiento de dicha organización en el exterior, que redundará en el aumento de la autoestima del personal, en un mayor reconocimiento social del trabajo, en la filosofía del compartir (propia de la escuela 2.0) y también en la consecución de los objetivos planteados.

Comunicación global, como concepto, ha sido acaparado por el mundo del marketing porque en realidad, en el mundo de las empresas, estos profesionales pertenecen al equipo de los que se ocupan de áreas relacionadas con la dirección de recursos humanos, relaciones públicas, responsabilidad social corporativa u otras con este cometido. En otras organizaciones, quienes se encargan de diseñar y seguir la comunicación global son, en primer lugar, la dirección, pero también el Departamento de Comunicación. 
Para WEIL (1992, p. 183) "la comunicación global es un buen instrumento para organizar todo el conjunto de una organización”. Las ventajas, además de ésta, son:

- Ayuda a dar coherencia al conjunto

- Combate el desorden comunicativo.

- Ayuda a la gestión global como proyecto organizativo.

- Aporta transparencia a la organización. Se trata también de compartir en beneficio general: hoy a través de las redes sociales y otros recursos digitales.

El poder que da la información en un centro escolar contribuye a un mejor funcionamiento si todos acceden a ella. La circulación de la información compete a todos y ayuda a ser un instrumento de trabajo, no de poder, mientras sea transparente y rápida.

Pero también la comunicación global implica:

- Una correcta planificación: es el objetivo principal de cualquier reflexión sobre el funcionamiento de la comunicación en las organizaciones, estudiar cuál es el funcionamiento para diseñar estrategias de mejora. Los cursos de dirección, estudios específicos, gabinetes especializados inciden en este aspecto, en demostrar el valor que tiene y cómo repercute positivamente en el funcionamiento y en los resultados. La planificación se debería incluir en el proyecto educativo de cada IE.

- Un compromiso por parte de todos. Es cierto que quien tiene el poder o la dirección accede a determinadas informaciones propias del cargo. Pero su difusión y uso adecuado también es una obligación del puesto, y más cuando son grupos que se mueven en ámbitos tan fundamentales como las organizaciones educativas de enseñanza obligatoria.

- La asunción de responsabilidades prácticas: podríamos aplicar aquella sentencia que manifiesta: “Decir obliga a hacer”.

- Coherencia y unos parámetros lógicos en la comunicación interna y externa de la organización educativa: es habitual la existencia de centros educativos con problemas comunicativos internos pero abundante y planificada comunicación externa para la potenciación de la imagen (real o manipulada), la captación de 
nuevo alumnado y la consolidación y apego de las familias que ya están dentro. Suele darse en centros en que la realidad interna es una, pero se publicita otra muy diferente hacia el exterior.

- Abrirse a nuevas tendencias que circulan en muchos ámbitos y que las IE deberían también propiciar, examinar y valorar sus posibilidades:

- Una nueva cultura aplicable al mundo de los centros escolares: se trata de desarrollar ideas y ponerlas al alcance de todos, darlas a conocer con las posibilidades que ofrece Internet: la web propia, la intranet, la revista digital, los blogs, los espacios en las redes sociales, etc.

- Enterarse de qué hacen otros centros, pero, al mismo tiempo, enseñar el nuestro. Compartir sobre todo las innovaciones y peculiaridades que puedan ser motivo de inspiración o adaptación fuera. Es la comunicación más global porque puede ayudar a otros y, a su vez, se ve enriquecida con nuevas aportaciones de ellos. Esta visión combate el mundo cerrado del aula, el saber guardado en cuatro paredes, el pretender inventar aquello que ya se está experimentando pero que, por desconocimiento, se pierde un tiempo muy válido que serviría para otras cuestiones.

- Cultivo de nuevas cualidades que ayuden a la mejora comunicativa: la empatía, la seducción, la inteligencia emocional y la capacidad de liderazgo. La comunicación global pasa por las personas y por sus potencialidades. Resulta difícil la mejora si quien la ha de llevar a cabo no se conoce a sí misma y, si es el caso, no se propone pequeñas metas que la ayuden a mejorar. En momentos difíciles, la aplicación de la resilencia es un gran recurso para sobreponerse con éxito a la situación. La escuela es una organización comunicante basada en personas. En este apartado hemos de referirnos también a otra de las asignaturas pendientes en las aulas: la inteligencia emocional.

La comunicación global en un centro educativo ha de tener en cuenta las reflexiones anteriores, unas fruto de la experiencia personal y otras extraídas de expertos en temas organizativos, conocedores de hacia dónde van las organizaciones. Son nuevas ideas que quizá causen extrañeza, sorpresa o incredulidad entre quienes se 
apegan a un funcionamiento tradicional propio de la rutina de cada curso, para quienes cualquier innovación es una complicación más que les desmonta la cotidianeidad ganada a fuerza de imposición y repetición (la "zona de confort"), o entre quienes dudan de las innovaciones que no hayan estado muy experimentadas, incluido este aparentemente nuevo concepto de Comunicación Global. En el fondo pretende, además de lo expuesto más arriba, unos objetivos concretos, ligados con la actividad docente, que cualquier profesional de la educación considerará importantes:

- Poner a disposición del profesorado todas aquellas informaciones necesarias para mejorar el funcionamiento del centro y la educación del alumnado.

- Establecer canales efectivos y planificados de comunicación para toda la comunidad educativa.

- Mejorar la estructura de gestión y de funcionamiento del centro.

- Favorecer la creación y circulación de opiniones e ideas que enriquezcan el centro y lo mantengan más activo, con la participación activa de la comunidad educativa.

- Mejorar el conocimiento externo y la difusión del trabajo que los profesionales de la enseñanza realizan con el alumnado.

- Dignificar la profesión docente ante la sociedad con la utilización de estrategias efectivas que partan del trabajo diario y de la intercomunicación.

- Contribuir al aumento del prestigio y, quizá, de la matrícula del centro a base de ese trabajo diario correctamente planificado.

Educar en comunicación digital implica que el alumnado conozca y practique el concepto "libertad de expresión" con responsabilidad. La democratización de las conexiones móviles obliga a concienciarse del impacto de la emisión de mensajes de todo tipo y a profundizar en las grandes posibilidades educativas que tienen los dispositivos como celulares y tablets (GONZÁLEZ, 2015b). También es necesaria la introducción de otros planos específicos de interpretación de lenguajes que favorezcan la inteligibilidad y la interpretación correctas:

- Los cambios que produce Internet respecto al papel en la lectura y escritura. 
- Lenguajes propios de asignaturas: es una actividad básica asociada a la materia. Los centros escolares intentan que los alumnos conozcan los términos semánticos propios de los códigos de cada asignatura. Son muchos los lenguajes específicos que se acumulan en un curso escolar.

- El lenguaje de las tecnologías de la información: imprescindible hoy. La tecnología, como la información, también conlleva ideología. Hay que ir más allá de acercar significados de palabras, consiste en interpretar el mensaje global y efectuar, si se puede, dobles lecturas e interpretaciones tanto de las palabras como del conjunto de los textos y de la llamada "lectura por capas".

- El lenguaje de las referencias y tendencias sociales vigentes: la actualidad, la moda, la publicidad, el marketing, los medios de comunicación, los cómics, los videojuegos, la música, tendencias como el piercing, los graffitis, los tatuajes, etc. La comunicación no verbal a menudo es otra gran olvidada.

- El lenguaje de las redes, las aplicaciones y los dispositivos (fijos y móviles): se han de dar pautas para mejorar su comprensión y aportar planos de significado, referencias acordes con su uso, valor y trascendencia social . A menudo el alumnado tiene claves de significado por el uso que el profesorado desconoce pero que sirven como elementos clave para una profundización colectiva. Un capítulo importante es el lenguaje de las aplicaciones como whatsApp, con la imposición de formatos semánticos y lingüísticos concretos que han de saber utilizar y discriminar en la práctica. Otro tema son los contextos que provocan las apps y los diferentes planos de significado. O sistemas de orientación como los gps, que hay que interpretar y usar como herramientas comunicativas de alto valor añadido en determinadas actividades y circunstancias. Los dispositivos están llenos de recursos, iconografías y utilidades que a menudo pasan desapercibidas.

- La lengua en las relaciones profesionales y personales de la comunidad educativa: es el intento de entenderse con códigos comunes inteligibles, evitar el uso de un lenguaje difícil de comprender para quienes forman parte del proceso comunicativo.

- La lengua en los procesos de control del aprendizaje del alumnado: a menudo las respuestas de los controles académicos a que se someten a los alumnos se ven mediatizadas por problemas de formulación: 
- La explicación inicial es incomprensible.

- Preguntas farragosas, formuladas de forma muy compleja, con varios apartados encadenados que resultan difíciles cuando el medio es el texto escrito. Ocurre lo mismo en preguntas orales.

- Preguntas orientadas más a la constatación de que se sabe repetir el concepto tal cual (que a veces no se ha entendido bien ni siquiera en su origen), que cuestiones dirigidas hacia los procesos, hacia la exposición de opiniones que impliquen la comprensión de los temas básicos que han de ser objeto del control, con una componente de generación de creatividad o de reflexión personal.

A menudo los sistemas de control del aprendizaje adquieren una denotación repetitiva y memorística que no implican la elaboración de nuevo conocimiento o la demostración de que se dominan procesos, metodologías y se han interiorizado habilidades. Un motivo para reflexionar es la valoración de un cambio en el planteamiento de los sistemas de evaluación, que deberían estar mediatizados por la innovación y por las TIC: con la posibilidad de usar google en los exámenes (CARABAÑA, 2015) y que los alumnos demuestren que consolidan la competencia "aprender a aprender".

\section{La introducción de cambios comunicativos}

Cualquier centro escolar que analice su funcionamiento, de manera formal o informal, establecerá una lista (ojalá más pequeña que grande) de aspectos mejorables. En el momento del diseño de estrategias para el cambio, la dirección debería introducir la innovación. Autores como TEJADA(1998), proponen seguir una serie de fases para ello: planificación, difusión o diseminación, adopción/adaptación, desarrollo o implementación y evaluación.

En primer lugar hay que entender el centro donde se llevará a cabo tal innovación. Muchos proyectos de calidad han chocado con personas o grupos que los han rechazado 
por el esfuerzo que suponía ponerlos en marcha y aplicarlos a la práctica o, simplemente, por la tradición y la comodidad. Por ejemplo con la metodología disruptiva (TORRES, 2015), the flipped classroom, Aprendizaje Basado en Proyectos (ABP), etc. En palabras de Joaquín Gairín (citado por TEJADA, 1998, p. 67):

[...] hay que comprender la organización de la institución en la que se quiere innovar para poder entender la innovación misma. Se hace preciso analizar las propiedades organizativas de la institución y su influencia sobre el comportamiento de los distintos miembros, descubriendo el conjunto de factores facilitadores u obstaculizadores del cambio pretendido y comprendiendo los aspectos estructurados y dinámicos de la institución, tanto en su dimensión interna como en su proyección y relaciones externas $[\ldots]$.

A partir de aquí, la innovación se ha de adaptar a tales circunstancias y diseñar las oportunas estrategias para darla a conocer como algo positivo.

En el campo que nos ocupa, la comunicación, la experiencia de profesionales de la enseñanza con cargos directivos y las reflexiones de autores como Tejada (1998) coinciden en apuntar algunos aspectos que se deberían tener en cuenta para introducir cambios a nivel comunicativo en un centro escolar:

- Los procesos comunicativos afectan a todas las estructuras del centro y a su organización. Se necesita un convencimiento general y una implicación global. Si la comunidad educativa no está convencida de la introducción de estructuras de este tipo, no funcionará el cambio.

- El profesorado ha de haber participado en su confección o, como mínimo, tener informaciones puntuales y claras de todo el proceso, dadas por personas con un alto nivel de credibilidad. Una estrategia que funciona es pedir la opinión de un experto, el cual, previamente informado, ratificará la innovación.

- Un cambio comunicativo importante exige una estructura muy clara, de tal manera que se sepa qué hacer, cómo colaborar y a quién dirigirse en cada momento.

- Los cambios se orientarán al centro pero también a las conductas de los profesionales. La dirección les facilitará un respuesta favorable que les refuerce su trabajo y autoestima. 
- Los cambios tendrán una visión a largo plazo. Exigen revisión-mejora-evaluación. Pero no se cuestionarán con frecuencia (trabajo del que se encargarán quienes se opusieron a la innovación, con el uso de las redes informales, de rumores y hasta de información reservada).

- La dirección apoyará los cambios, propiciará la motivación de todos para conseguir lo propuesto y resaltará los logros, por pequeños que sean. Si la dirección no es un motor favorecedor de los cambios, poco se conseguirá. Ante cualquier problema que surja, se explicará la forma de solucionarlo en vez de recrearse con las dificultades aparecidas.

- Los cambios exigen apoyos de todo tipo. La Administración educativa es la primera que debe ponerse al frente de los centros para ayudarles a mejorar, con el mayor número de recursos. No sólo con palabras vacías, sin comprobaciones prácticas (en el caso de los centros privados, sirve también para sus propietarios o titulares).

- Los cambios necesitan implicación y una estructura comunicativa clara y abierta. Es mejor ir poco a poco, de menos a más.

\section{La educomunicación con las TIC en la sociedad global}

El uso de las TIC en las aulas abre los centros educativos a la realidad. Las tecnologías son ventanas que provocan la desaparición de las paredes en contextos de fluidez y de contacto continuo con la realidad, en la que actualidad juega un papel muy destacado. Las noticias de cada día son una gran fuente pedagógica que convierte el aprendizaje en competencial y significativo. Un alumno que ve cómo el centro le explica los acontecimientos y observa cómo le aporta claves para su contextualización e interpretación, dispondrá de estrategias para adoptar actitudes críticas ante los poderes dominantes y será capaz de evitar engaños o manipulaciones.

Le educación en comunicación digital, de entrada, se basa en los cambios que produce Internet a la hora de leer y escribir (GONZÁLEZ, 2015C), un aspecto sobre el que hay que incidir para observar las diferencias respecto al soporte papel y la adaptación. El 
uso de los medios de comunicación y de otras fuentes informativas va implícito. El llamado por algunos "periodismo ciudadano" es una realidad comunicativa, criticada por ciertos profesionales de los medios pero ya habitual debido a las peculiaridades de Internet. Los alumnos se informan de diversas maneras: cada vez menos por los periódicos en papel y más por vía redes sociales, se alejan del consumo de televisión (FERNÁNDEZ, 2015) o lo hacen solo a la carta vía webs y plataformas, las recomendaciones digitales, la elección de fuentes seleccionadas, los contactos, los clips de actualidad, la mensajería instantánea y los efectos virales. La educomunicación obliga al docente a estar informado, a conocer por dónde le llega la actualidad a sus alumnos, qué temas les interesan y qué entienden de cada tema según los canales, para ayudarles a efectuar una correcta interpretación de los hechos y de los temas.

El uso de la prensa digital como recurso educativo en el aula parte de algunas incógnitas sobre cómo se construye el conocimiento, cuáles son los efectos de las tecnologías en los hábitos vitales, cómo se redacta hoy en formato multimedia y cómo se explica la actualidad, o qué son y qué no son los medios de comunicación hoy día. Ello, desde el propósito final de dar luces en torno a la interesante ¿Para qué usar el ciberperiodismo o periodismo digital en las aulas?:

- Para descubrir: la realidad que transmiten los medios y cómo la interpretan, la globalización informativa, los procesos informativos y su mediatización y la transversalidad de la información.

- Para pensar: en esos procesos, en la inmediatez y en la perdurabilidad de las informaciones, en la influencia de los medios en la opinión pública, en la interpretación individual y social y en aportar pautas para saber cuál es el papel de cada uno ante el enjambre informativo.

- Para comunicar: por medio de la lengua; cómo construir el relato informativo con recursos como la hipertextualidad, la interactividad, la multimedialidad y la actualización periódica; para interactuar y compartir.

- Para reflexionar: con criterios, como recurso; con valores humanos en nuestras actuaciones. 
Desde hace trece años hasta hoy están en marcha experiencias del uso del periodismo digital (ROSELL, 2007) y de la escritura creativa en las aulas, por ejemplo en la institución educativa pública Torre del Palau de Terrassa, Barcelona, España. La creación, hace trece años, de una asignatura específica dedicada a la práctica de ciberperiodismo con blogs entre alumnado de doce años fue referenciado por autores como GONZÁLEZ (2004) y en medios de comunicación DOMíNGUEZ (2007). Si bien el objetivo central era la actualidad externa, el proyecto revertió en la comunicación global del centro, a la que nos referíamos anteriormente. El alumnado y el profesorado participaron en la aplicación de las técnicas periodísticas para difundir las actividades que se hacían en el centro a través de una revista digital creada para la ocasión, con una estructura externa como la de cualquier diario, alimentada internamente con una aplicación que se basaba en una redacción de alumnos, abierta a colaboraciones de toda la institución. Recibían textos y fotos y aplicaban los conocimientos de la asignatura para la edición digital y la publicación definitiva. La aplicación permitía a los profesores y a los alumnos escribir comentarios o ampliar las informaciones con la aparición de su nombre debajo. Se pretendía educar en la responsabilidad para evitar refugiarse en el anonimato.

Desde blogger se comenzaron a crear blogs personales con una finalidad informativa. También servían como portafolios digital con el objetivo de acompañar al alumno a lo largo de su escolaridad. Todos estaban enlazados y eran públicos para favorecer su consulta, profundizar en el conocimiento de cada alumno (identidad digital) y acceder a una muestra representativa de los mejores trabajos realizados en clase. El proyecto continúa hoy día. La calidad de los blogs más recientes depende de la insistencia del profesor y de la implicación del alumno. Actualmente también se usan otras herramientas de difusión cuando las condiciones de uso y edad lo permiten: booktubers, infografías, archivos de sonido, presentaciones multimedia, aplicaciones, hastags específicos en Twitter y otras propuestas novedosas que van apareciendo y de las que a los alumnos informan a los profesores. 


\section{Las redes sociales en las instituciones educativas}

En diferentes sectores educativos existe cierto temor al uso de Facebook y Twitter entre el alumnado no universitario. Los rectores y directivos de las IE suelen fijar los criterios de funcionamiento en los proyectos educativos o líneas programáticas que definen el reglamento interno. Todas las posturas son respetables pero hoy la comunicación digital no se puede entender sin Facebook, Twitter y otras redes sociales en una sociedad global, dentro de los límites legales que definen en su política de uso. Las ventajas son evidentes, también los peligros (GONZÁLEZ, 2016). Nuestra postura en la IE Torre del Palau es la de educar desde la responsabilidad, no con la prohibición. Esta forma de proceder la extendemos al uso de los teléfonos celulares en las clases y a la posibilidad de que alumnos y profesores usen la wifi del centro de forma gratuita cuando quieran. Existen unas normas que regulan la libertad, con el objetivo de conseguir ciudadanos responsables en el uso de la tecnología .

Utilizamos (o podemos usar) Facebook y Twitter con el alumnado en algunas clases, con aquellos profesores innovadores que están convencidos del poder de las redes sociales (que ya usan los alumnos fuera del centro) también para aprender y educar. Los resultados son muy positivos. Se han hecho (y se pueden hacer) experiencias también con la aplicación de mensajería whatsapp (mayores de 16 años).

Por otro lado, la política comunicativa de la IE se basa desde hace tiempo en estas dos redes sociales (la lengua preferente de nuestra presencia en Facebook y Twitter es el catalán), con muchos seguidores y con un impacto eficaz e inmediato. Básicamente hasta ahora se usan para colgar informaciones (texto, fotos y vídeo) producidas dentro de la institución educativa, impactos del centro en los medios de comunicación y también se experimenta con novedades: ofrecer a las personas seguidoras formación, bien sea sobre Internet segura, ciberbuying, conductas adolescentes, cómo estudiar con las tecnologías, etc. Se publican consejos y enlaces a páginas web especializadas o se ofrecen presentaciones producidas en el centro con contenidos básicos. La experiencia es un éxito si nos guiamos por el número de visitas que contabilizan los administradores, con lo que se demuestra que los cambios en el uso de las redes sociales exigen la introducción de otras prácticas que, por otra parte, dan respuestas a cuestiones que el público se 
plantea o que descubre. Desde el punto de vista del marketing y de la imagen de la institución educativa, se refuerza su impacto ante la opinión pública, los efectos de las actividades efectuadas penetran aún más en la sociedad y se aumenta la integración y el espíritu de grupo, con la posibilidad de participar con los comentarios.

\section{Educar en comunicación digital con los dispositivos móviles}

La penetración de los dispositivos móviles como los celulares y los tablets en América Latina es imparable, con gran adicción a redes sociales como Facebook (GRANADOS, 2015), hasta el punto de que las tendencias sociales y económicas se mueven hacia aplicaciones donde la comunicación instantánea, la información y los servicios provocan cierta dependencia. Los niños y adolescentes ya casi los consideran objetos imprescindibles y a menudo los usan como si de un juego se tratara, sin tener en cuenta su poder y los efectos que conlleva una mala utilización.

En las IE poco a poco hacen acto de presencia, con respuestas contradictorias por parte de los rectores y del resto de la comunidad educativa. Mientras en muchos casos se tiende a prohibirlos o ignorarlos, abundan ya experiencias pedagógicas que confirman su gran potencial educativo. Los celulares aún están por descubrir de forma general en la enseñanza, si bien ya hay muchas apps específicas para atender diferentes momentos del aprendizaje y el hecho de estar siempre conectado a Internet es una excelente ocasión para el aprendizaje continuo. El reto está en la demostración de su eficacia desde la práctica del aula. Se necesita una infraestructura de conectividad adecuada, formación del profesorado, voluntad de los rectores de las IE, complicidad de las familias y demostraciones efectivas de que son mucho más que máquinas para enviar mensajes o estar presentes en las redes sociales. Desde la experiencia del uso en el aula, los celulares también sirven para educar y aprender en clase (GONZÁLEZ, 2015). Sorprende cuando alguien aporta argumentos en su defensa en un encuentro de profesores (GONZÁLEZ, 2014) o cuando se documenta su valor educativo con proyectos desarrollados por alumnos no universitarios de la IE Torre del Palau. En concreto se trata de una aplicación para la mejora de la información turística de la ciudad (SALGUEIRO, 2012), para ser usada 
con los celulares. El presente de la educación está en todas partes pero también en el bolsillo de nuestros alumnos.

Como conclusión, las IE han de estar atentas a la evolución de la sociedad global y preparar a sus alumnos para vivir en un entorno desconocido pero cambiante, donde el dominio de competencias y habilidades será imprescindible, la adaptación a las circunstancias obligará a tener una mente abierta y la información circulará por doquier. La comunicación digital aún será más ubicua pero también exigirá aprender a aprender y hacerlo a lo largo de toda la vida en espacios presenciales o virtuales donde ha de prevalecer el encuentro entre las personas. En palabras de Paulo Freire (FERNÁNDEZ, 1999): “La educación es comunicación, es diálogo en la medida en que no es transmisión de un saber, sino un encuentro de sujetos interlocutores que buscan la significación de los significados".

\section{Referencias}

BARTOLI, Annie. Comunicación y organización. Barcelona: Editorial Paidós, 1992.

CARABAÑA, Carlos. Utilizar Google en los exámenes, ¿futuro o patinazo? Madrid: diario EL PAÍS, mayo, 2015. http://elpais.com/elpais/2015/05/12/icon/1431428249_672003.html

CARR, Nicholas, Superficiales: ¿qué está haciendo Internet con nuestras mentes? Madrid: editorial Taurus, 2011.

CORNELLA, Alfons. Infoxicación. http://alfonscornella.com/thought/infoxicacion/ . 2013.

DANS, Enrique. Blog http://www.enriquedans.com

DOMÍNGUEZ, Eva. Aprender con el método periodístico. Barcelona: diario La Vanguardia, diciembre, 2007. http://blogs.lavanguardia.com/elcuartobit/aprender-con-el-metodoperiodistico

FERNÁNEZ, Alejandro. Planificación ético-estratégica para el desarrollo de los activos intangibles en las organizaciones. Web Diario Responsable, noviembre, 2012. http://diarioresponsable.com/opinion/16036-reputacion-corproativa-planificacion-eticoestrategica-para-el-desarrollo-de-los-activos-intangibles-en-las-organizaciones

FERNÁNDEZ, Juan Manuel. Paulo Freire: una propuesta de comunicación para la educación en América Latina. México: revista Razón y Palabra, enero-marzo, 1999. http://www.razonypalabra.org.mx/anteriores/n13/freirem13.html 
FERNÁNDEZ, Nuria. Los jóvenes se alejan del consumo de información a través de la televisión. Barcelona: Gabinete de Comunicación y Educación, octubre 2015. http://www.gabinetecomunicacionyeducacion.com/es/noticias/los-jovenes-se-alejan-delconsumo-de-informacion-traves-de-la-television

GONZÁLEZ, Evaristo. La comunicación global en educación: de las webs a los centros docentes. Barcelona: Departament d'Ensenyament, 2001.

http://redined.mecd.gob.es/xmlui/handle/11162/16290

GONZÁLEZ, Evaristo. Si us plau, encén el móvil quan entris a clase. Barcelona: portal Diari de l'Educació, noviembre, 2014. http://diarieducacio.cat/blogs/bofill/2014/11/21/si-us-plauencen-el-mobil-al-entrar-classe/

GONZÁLEZ, Evaristo. Educar en comunicación con los periódicos digitales. Huelva: revista Comunicar, 2004. http://www.redalyc.org/articulo.oa?id=15802223

GONZÁLEZ, Evaristo. La transformación de los centros educativos en la era digital. Bogotá: portal Colombia Digital, julio, $2015 a$.

http://www.colombiadigital.net/opinion/columnistas/item/8419-la-transformacion-de-loscentros-educativos-en-la-era-digital.html

GONZÁLEZ, Evaristo. Los celulares también sirven para educar y aprender en clase. Bogotá: Portal Colombia Digital, agosto 2015b.

http://www.colombiadigital.net/opinion/columnistas/desde-afuera/item/8464-loscelulares-tambien-sirven-para-educar-y-aprender-en-clase.html

GONZÁLEZ, Evaristo. Internet obliga a enseñar en las aulas otras formas de leer y escribir. Bogotá: Portal Colombia Digital, octubre 2015C.

http://colombiadigital.net/opinion/columnistas/desde-afuera/item/8561-internet-obliga-aensenar-en-las-aulas-otras-formas-de-leer-y-escribir.html

GONZÁLEZ, Evaristo. El uso de redes sociales en los centros educativos. Bogotá: portal Colombia Digital, enero 2016.

https://www.colombiadigital.net/opinion/columnistas/desde-afuera/item/8702-el-uso-deredes-sociales-en-los-centros-educativos.html

GRANADOS, Óscar. Latinos adictos al Facebook. Madrid: diario El País, octubre 2015. http://economia.elpais.com/economia/2015/10/og/actualidad/1444377806_773680.html

HERNÁNDEZ, Tibisay. La telefonía móvil como medio de inclusión social. Portal Colombia Digital, septiembre 2015. http://www.colombiadigital.net/opinion/columnistas/desdeafuera/item/8488-la-telefonia-movil-como-medio-de-inclusion-social.html

INFANTE, Isabel. El lenguaje del rostro y de los gestos. Madrid: Editorial Quorum, 1986. 
ROSELL, Laura. Alumnos de un instituto de Terrassa participan en un proyecto de medios digitales. Madrid: diario EL PAÍs, septiembre, 2007.

http://elpais.com/diario/2007/og/13/ciberpais/1189650932_850215.html

SALGUEIRO, José Antonio. El uso educativo de la Realidad Aumentada aplicado a la información turística. Madrid: blog de buenas prácticas del Ministerio de Educación, septiembre, 2012.

SERRANO, Sebastià. Comprender la comunicación. Barcelona: Editorial Paidós Ibérica, 2000.

TEJADA, José. Los agentes de la innovación en los centros educativos: (profesores, directivos y asesores). Archidona (Málaga): Editorial El Aljibe, 1998.

TORRES, Ana. “La Universidad se ha convertido en una fábrica de certificación”. Diario EL PAÍS (Madrid): octubre 2015.

http://economia.elpais.com/economia/2015/10/23/actualidad/1445599771_649955.html

WEIL, Pascale. La comunicación global: comunicación institucional y de gestión.

Barcelona: Editorial Paidós Ibérica, 1992. 